\title{
Operational Modal Analysis: A Tool for Assessing Changes on Structural Health State of Historical Constructions after Consolidation and Reinforcement Works-Jura Chapel (Jerez de la Frontera, Spain)
}

\author{
Manuel Romero, ${ }^{1}$ Pablo Pachón $\mathbb{D D}^{1}{ }^{1}$ Víctor Compán, ${ }^{1}$ Margarita Cámara, ${ }^{1}$ \\ and Francisco Pinto ${ }^{2}$ \\ ${ }^{1}$ Department of Continuum Mechanics, University of Seville, Avenida Reina Mercedes, 41012 Sevilla, Spain \\ ${ }^{2}$ Department of Architectural Graphic Expression, University of Seville, Avenida Reina Mercedes, 41012 Sevilla, Spain \\ Correspondence should be addressed to Pablo Pachón; ppachon@us.es
}

Received 25 May 2018; Accepted 12 July 2018; Published 26 August 2018

Academic Editor: Luca Z. Fragonara

Copyright (c) 2018 Manuel Romero et al. This is an open access article distributed under the Creative Commons Attribution License, which permits unrestricted use, distribution, and reproduction in any medium, provided the original work is properly cited.

\begin{abstract}
Today's society is sensitive to the architectural heritage conservation. This implies to perform works to maintain these buildings and to assure their structural security. In the last years, the structural analysis of historical masonry constructions has experienced a great progress, thanks to the use of techniques based on the study of the dynamic properties of building structures. In this context, changes on the structural health state of a building are one of the elements that can be assessed considering changes on their dynamic properties. This is useful to evaluate the effectiveness of structural interventions on this kind of buildings by analysing these properties before and after it. This paper focuses on the Jura Chapel, in Jerez de la Frontera (Spain). This chapel is part of San Juan de los Caballeros Church and is dated from the 15th century. In 2015 and after the identification of some structural damages in the chapel vault, an intervention was initiated to improve its structural behaviour and to recover its original appearance. The present work reports the evaluation of the effects that this intervention has on the structural health state of the building, using nondestructive techniques based on ambient vibration tests (AVT) and Operational Modal Analysis (OMA). The AVT were performed for both prerestored and restored states and under environmental loads. A discussion about the validity of doing AVT from extrados when a vault presents disconnection between ribs and web is included in the paper. As a result, the first five natural frequency values have increased while the corresponding mode shapes have not changed significantly. This proves a structural health improvement caused by the repairing process without changing the original behaviour of the structure. This work shows OMA capabilities for evaluating the effectiveness of intervention works on the health state of a historical masonry structure.
\end{abstract}

\section{Introduction}

Nowadays, it is a fact that modern societies are greatly interested in preserving architectural heritage, one of the most important links between ancient and current generations. In order to protect it and assure structural security, this heritage has to be maintained and, if necessary, repaired, so various technical works are often required. However, building restorations can be ineffective and fail to produce the expected improvements on the structures. Consequently, the effects of restorations on the structural behaviour of historical structures should be assessed in order to guarantee their effectiveness.

This assessment can be carried out considering the changes that an intervention causes on the dynamic properties of a structure, as many identified changes on these properties can help to evaluate how the intervention has modified the structural health state of the historical building. In this sense, Operational Modal Analysis (OMA) is a useful tool to identify the modal parameters of a historical structure 
[1]. This is a nondestructive technique, which works only under ambient vibration, so it does not create any negative effect on the measured structures, being respectful with heritage. By doing OMA at least before and after the restoration process, changes on the dynamic properties of the structure can be identified and analysed. These changes can be easily detected as the dynamic behaviour is sensitive to any alteration to geometrical dimensions, boundary conditions, mass, and/or mechanical properties of materials.

In the last decade, there have been many cases of ambient vibration test applications in historical buildings [2-10]. However, OMA applications for evaluating structural interventions in historical buildings are more limited: from 2011 to 2013, the control of the intervention carried out in the area of the Roman Theatre of Cádiz (Spain) was done by means of ambient vibration tests [11]; in 2012, Osmancikli et al. [12] studied the effects of the restoration of the belltower of Hagia Sophia Church in Trabzon (Turkey); likewise, in 2014, Çalık et al. [13] presented the evaluation of the restoration process of the masonry vault of Küçük Fatih Mosque, also located in Trabzon. In all these cases, the effects of the restorations were evaluated by comparing the dynamic characteristics before and after the repairing of the buildings and using OMA.

This paper focuses on the Jura Chapel (Jerez de la Frontera-Cádiz, Spain). The chapel is a heritage building dated from the beginning of the 15th century and is part of San Juan de los Caballeros Church (Figure 1), one of the six historic churches promoted by King Alfonso X in Cádiz. In 2015, the chapel showed damages such as cracks on the walls and the vault webs. An intervention was then carried out in order to recover a proper structural behaviour and the original appearance of the chapel.

The main purpose of this study is to evaluate the effects of an intervention carried out in 2015 on the structural health of the Jura Chapel by using nondestructive techniques based on ambient vibration tests and Operational Modal Analysis.

The paper is organised as follows. Section 2 summarises the main characteristics of the Jura Chapel together with a historical overview and a brief description of the structural intervention. Section 3 describes the followed methodology to achieve the main purpose of the study. Section 4 describes the ambient vibration tests and some preliminary tasks that were carried out to improve the accuracy in the identification process. Section 5 describes the identification of modal parameters. Section 6 discusses the obtained results and, finally, Section 7 presents the conclusion drawn from the research.

\section{Jura Chapel: History, Architectural Configuration, and Consolidation Works}

The Jura Chapel adjoins the apse of the San Juan de los Caballeros Church in Jerez de la Frontera (Cádiz, Spain) (Figure 2). It was built in 1404 , as a description in the foundational records confirms [14]. From 1404 until 1890, the chapel operated as such, opening on to the church chancel. During the course of this period, it suffered the

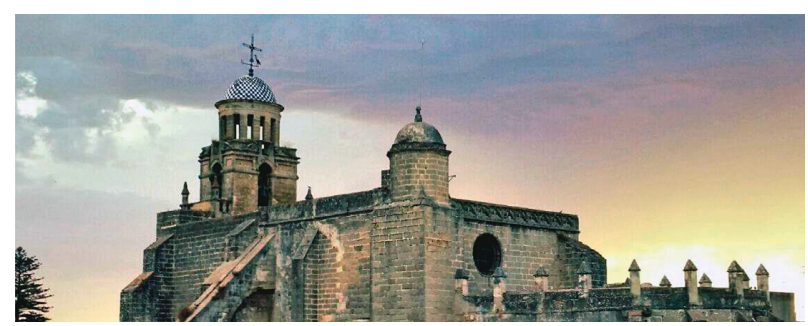

Figure 1: San Juan de los Caballeros church, Jerez de la Frontera.

consequences of the remodels that were carried out in the rest of the church, such as the construction of the first tierceron vault of the nave, which rested on the chapel walls (1504).

The most recent interventions were carried out during the remodel that took place in the nineteenth century, between 1890 and 1895. It was an attempt to solve the building's serious structural problems that had been detected. The chapel walls and foundations were reinforced, and the arch through which the chapel and the chancel communicated was blinded. However, the works were never fully completed due to lack of funding, and since then the chapel has been neglected, eventually becoming just another room in the parish priest's house [15]. In 2006, during the restoration of the aforementioned parish house, some damages were identified in the chapel. First, there were some cracks in the corner walls of the chapel (A-7-9 and 9-A-C; Figure 2). Second, it was detected a misalignment in the voussoirs of the vault ribs closest to the apse wall, as well as disconnections between the ribs and the masonry webs.

The Jura Chapel's external appearance adopts the form of a quadrangular prism-shaped volume completely covered by its vault and practically devoid of ornamentation. The complete volume, about $10.30 \mathrm{~m}$ high, is lower than both the church chancel and the adjacent parish house. The interior space extends laterally via three pointed arches embedded in the walls. These walls consist of two external stone masonry layers filled with stone rubble, pieces of ceramic material, and a sand-and-lime mortar, reaching a total thickness of $90 \mathrm{~cm}$. Actually, the embedded arches reduce the walls' thickness to $36 \mathrm{~cm}$. With regard to the vault, it counts on a height of $8.74 \mathrm{~m}$ and a width of $6.85 \mathrm{~m}$. It is an octagonal stellar vault with $45 \mathrm{~cm}$ high stone ribs and $12 \mathrm{~cm}$ thick brick webs (Figure 3). The webs generate a unified hemispherical shell on the ribs. This vault is differentiated from the walls by a continuous stone cornice, and the transition from the square-plan floor to the octagonal vault is achieved by four brick squinches.

Each vault rib rises independently until it meets the other at a right angle, producing a curious point of union resolved without a special piece. A sand-and-lime mortar was used to simulate the continuity between each three arches that meet. This mortar was also used to cover misalignments between the ribs and the web. The movement of the vault caused the collapse of the mortar in one of the voussoirs, and this fact discovered this unusual constructive solution (Figure 4). The aforementioned building solution displaces the line of thrust of the ribs to their upper 


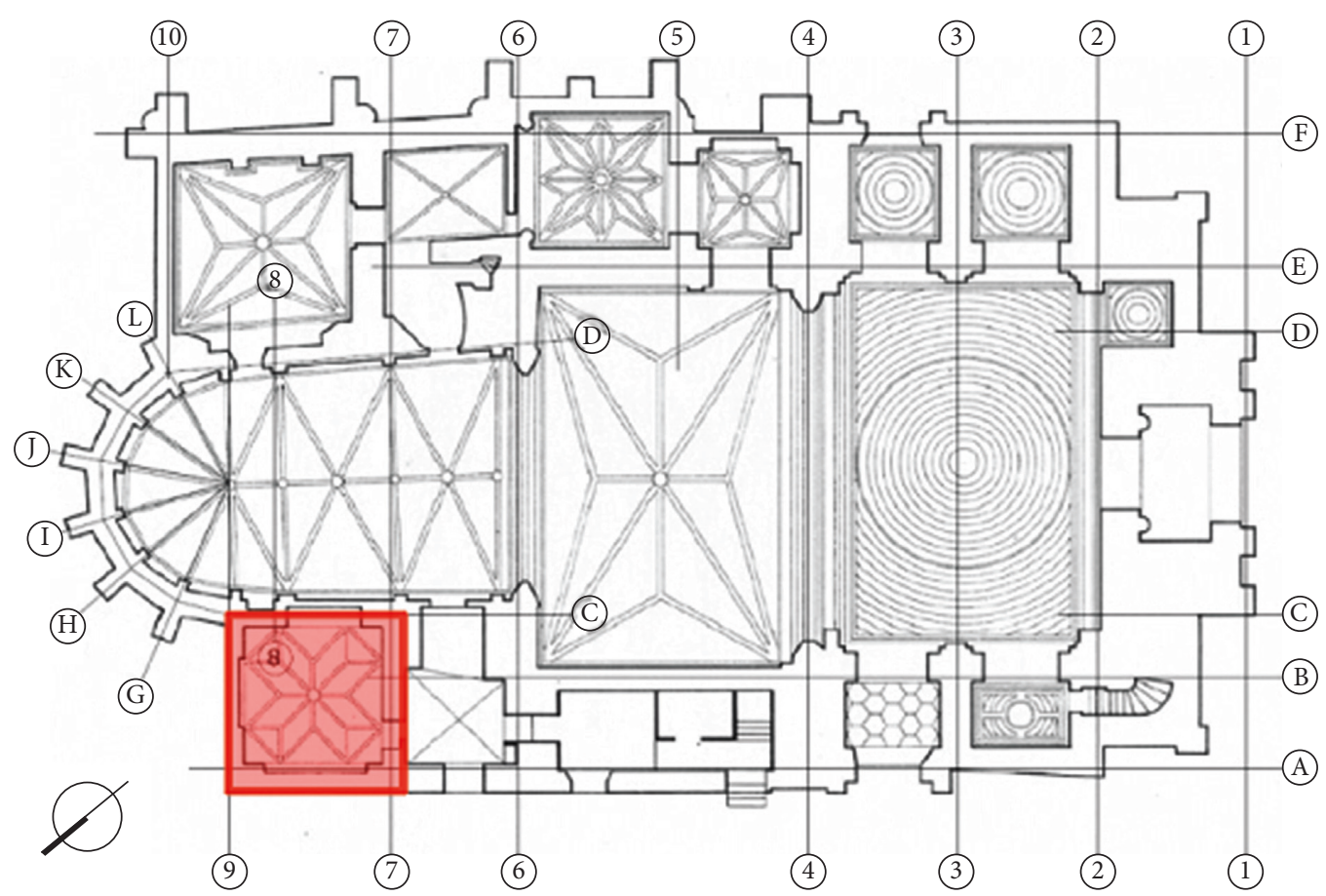

FIgURE 2: Original plan of the San Juan de los Caballeros church-Jura Chapel in red.

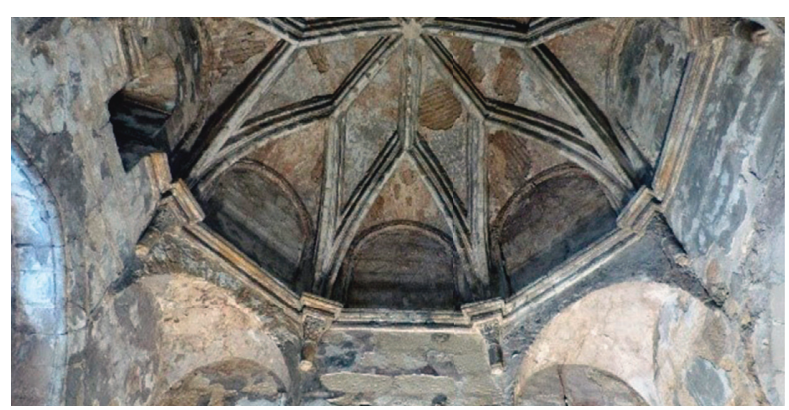

(a)

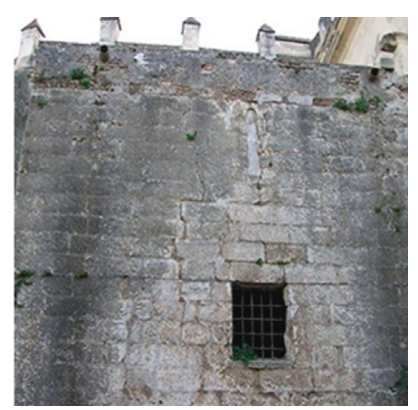

(b)

FIGURE 3: Interior and exterior views of the Jura chapel.

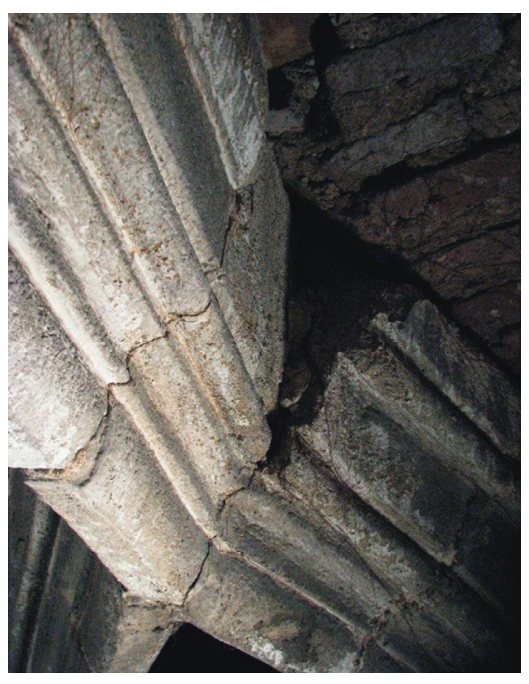

(a)

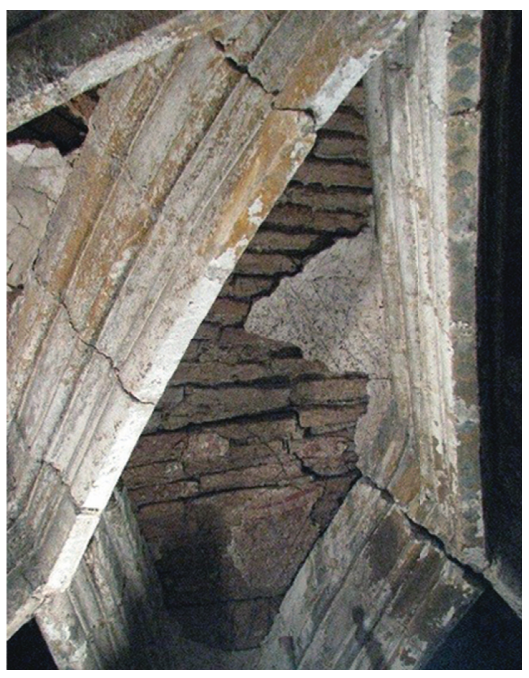

(b)

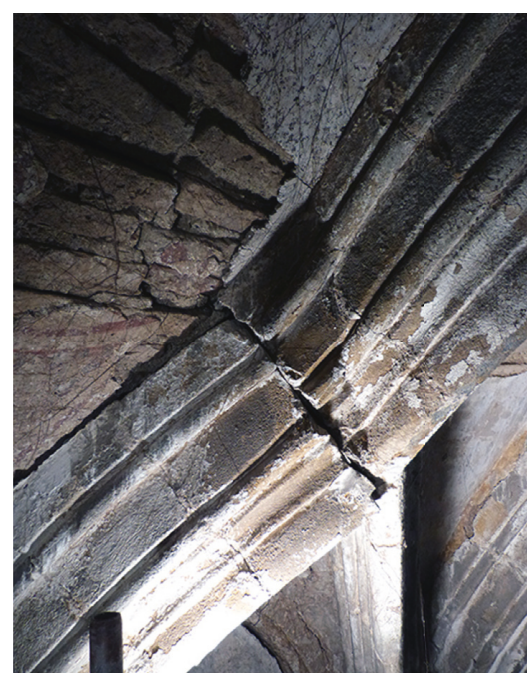

(c)

Figure 4: Joint between ribs and voussoir devoid of ornamentation. 


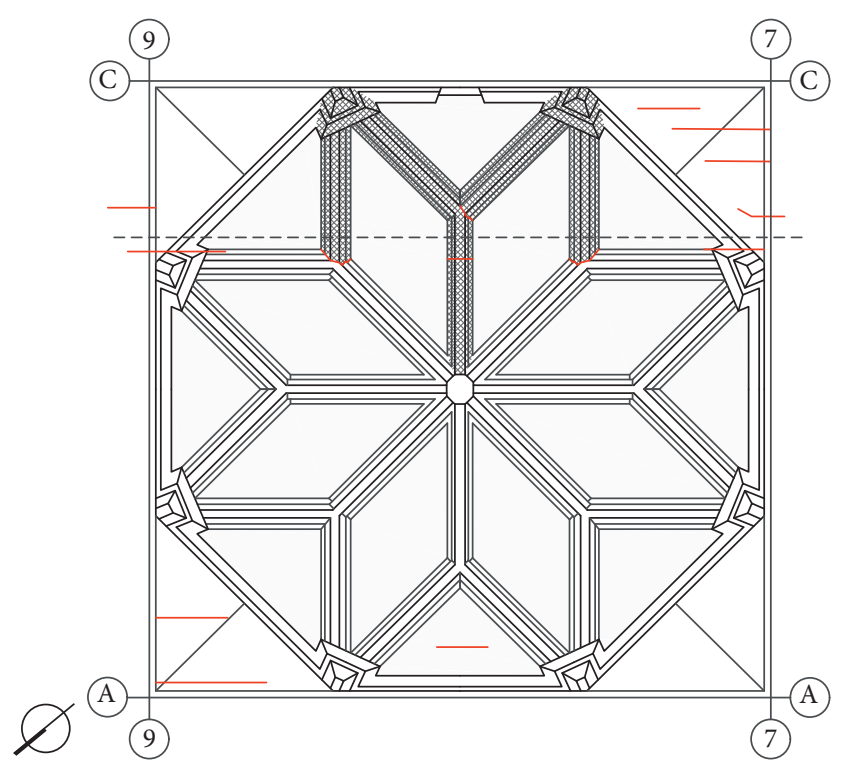

Figure 5: Plan of the chapel vault. The shaded area indicates the ribs affected by the movements, the red lines indicate the cracks mapped, and the dotted line illustrates the relationship between the cracks in the vault and the side walls.

part, thus decompressing the intrados. Figure 5 shows the fissures in the ribs, which are associated with the damages detected on the walls of the northern corner.

The intervention focused on consolidating the structural unity of the chapel using minimally invasive techniques. The first step was to clean the walls and the vault webs, making it easier to identify the cracks and fissures. In the case of the walls, the cracks were sewn together using carbon fibre bars with a diameter of $8 \mathrm{~mm}$. The length of these bars varies between 100 and $150 \mathrm{~cm}$ (Figure 6). They were placed transversally and along each of the cracks, at a depth of approximately $15 \mathrm{~cm}$ with respect to the exterior wall. Likewise, the most deteriorated ashlars were replaced. Regarding the consolidation of the vault web, the joints between the bricks were cleaned and refilled with sandand-lime mortar. This same procedure was repeated with the joints between the voussoirs in the vault. With regard to the vault, the only arches that were sewn to the web were the lower ones. This task was performed at each joint, where the greatest displacement of the voussoirs had occurred. In this case, $8 \mathrm{~mm}$ diameter stainless steel bars were used to do this.

\section{Methodology}

To evaluate the effects of the intervention on the structural health of La Jura Chapel, two ambient vibration tests were initially proposed, one before the intervention process and the other after it. The aim of these experimental campaigns was the identification of natural frequencies and mode shapes of the vault at each one of these stages and for a later comparison between them. Equation (1) shows the relationship between natural frequency $f_{n}$, structural stiffness $K_{n}$, and the mass $m$. In the case of this chapel, the increasing

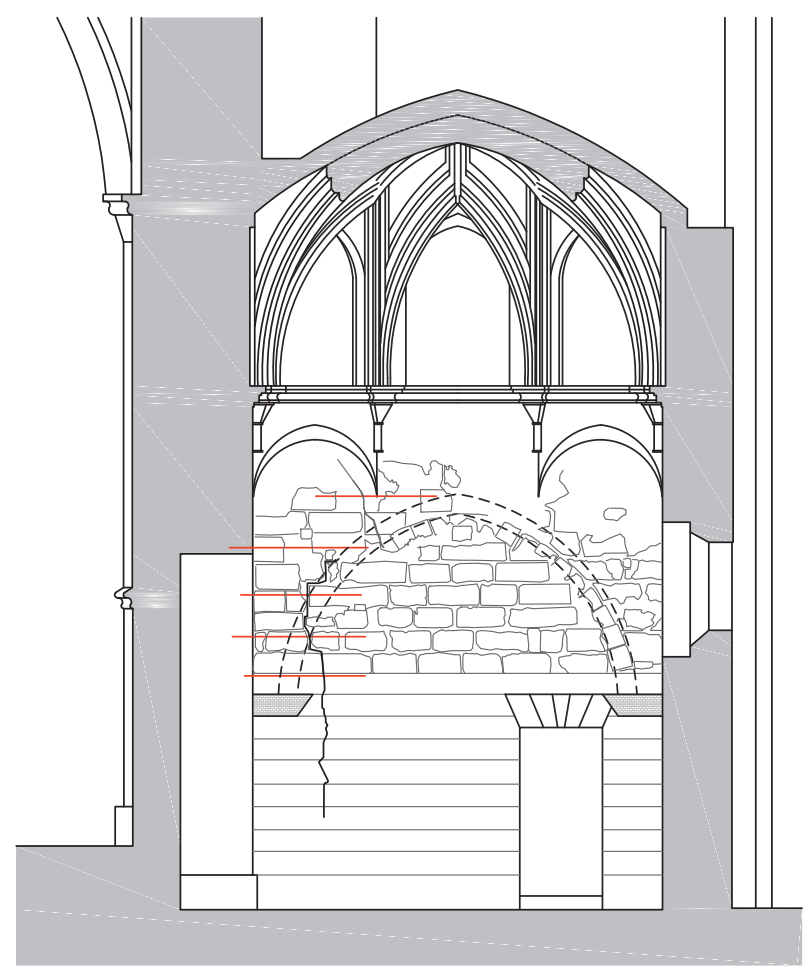

Figure 6: Position of the bars sewn with carbon fibre bars: wall 7-A-C.

of the mass after the intervention has been about $12 \%$ and is due to the gypsum plaster. This increasing will be taken into account during the comparative analysis of frequencies before and after the restoration process and the corresponding interpretation with regard to modifications in the stiffness of the structure.

$$
f_{n}=\sqrt{\frac{K_{n}}{m}}
$$

On the other hand, the identification of the mode shapes will be useful in order to check if the intervention has significantly changed the original structural behaviour. The corresponding experimental campaigns were initially projected to be done on the extrados of the chapel vault. This is the most common way to take this kind of measurements in vaults [16], due mainly to two reasons: first, the accessibility is usually easier and auxiliary equipment such as scaffolds or lifting platforms are not necessary; second, some vault intradoses count on decoration, which could be damaged during the fixing of the accelerometers.

However, in this case, there were visual evidences of a structural disconnection between vault ribs and the brick web at some points (Figure 4). This made one suspect that taking measurements on the vault extrados could not provide correct data to make a proper analysis. This was the reason why experimental campaigns by positioning accelerometers directly on the ribs from the intrados became the most reasonable option to reach the main aim of this study. As it has been explained before, the vault did not count on decoration so the accelerometers could be fixed without problems in this case. 
From this argument, a secondary objective related to the methodology was adopted in this work. This is the demonstration of the hypothesis that taking measurements from the extrados of a vault is not valid when a suspicion of disconnection between ribs and web exists. To achieve this secondary objective, it is necessary, on one hand, to analyse dynamic properties obtained from both intrados and extrados when there is a suspicion of disconnection between elements, that is, before the intervention. On the other hand, an analogous procedure will be performed but, in this case, when the connection between these elements is expected, that is, after the intervention.

Four ambient vibration tests were thus carried out: two of them before the structural intervention and from the intrados and extrados, and the other two after the structural intervention and, in the same way, from the intrados and the extrados.

\section{Experimental Setup}

Experimental campaigns before and after intervention works took place in April and September 2015, respectively. All of them were performed under similar temperature and humidity conditions in order to avoid variations in the identified modal parameters [17]. Likewise, the excitation was always associated with environmental loads (Figure 7).

As it has been explained above, the identification was carried out on the chapel vault. It was an identification of the dynamic properties in a very local area, which is integrated in a much larger whole. This fact can make the identification difficult, and the resulting mode shapes could be less clear. That is why two tasks were conducted in order to improve the precision of this identification:

(1) Before intervention, the chapel vault counted on a specific deformation state, so a geometrical model built from coordinates based on a theoretical geometry would not be accurate. In order to improve the identification of the dynamic properties, a photogrammetric model [18] was developed to precisely determine the $X Y Z$ coordinates of the accelerometers' position (Figure 8). From this model, it could be confirmed that the difference between theoretical and original coordinates reaches up to $6 \mathrm{~cm}$.

(2) A suitable determination of the reference points of the experimental campaign can also improve the identification process [1]. Previously to the experimental campaign, a finite element model (FEM) was developed in order to conduct a subsequent structural analysis that is not a subject of this work. A preliminary modal analysis was done by using this model in order to identify which points suffered greater modal displacements in as many vibration modes as possible (Figure 9). Figure 10 shows a representation of the considered measuring points and highlights in blue points 2 and 12 as the reference ones.

Regarding the sensor layout, it can be seen in Figure 10 that the total number of measuring points in each experimental campaign is 17. All of these points were set in the three principal directions in order to also capture the global vibration modes of the vault in the longitudinal, lateral, and vertical direction. As the total number of accelerometers was six and considering that two of them were held stationary for reference measurements, a series of nine setups in each stage were necessary to cover all measuring points. In each one of these setups, the accelerations were recorded with a sampling rate of $100 \mathrm{~Hz}$ and a sampling time of $12 \mathrm{~min}$. The measuring points that correspond to the ambient vibration tests from the extrados are analogous to those in Figure 10. Their coordinates are the result of the normal projection of these last points on the extrados surface.

The equipment used for these tests consists of six uniaxial force balance accelerometers, with a bandwidth ranging from 0.01 to $200 \mathrm{~Hz}$, a dynamic range of $140 \mathrm{~dB}$, a sensitivity of $10 \mathrm{~V} / \mathrm{g}$, and $0.35 \mathrm{~kg}$ of weight (model ES-U2). They were connected by eight 40 -metre coaxial cables to a 12-channel data acquisition system with a 24-bit ADC, provided with antialias filters (model GRANITE, KINEMETRICS) (Figure 11).

\section{Identification of Modal Parameters}

The in situ obtained data were processed with the software ARTEMIS [19] by using two different identification methods: the Enhanced Frequency Domain Decomposition (EFDD) technique (Figure 12) and the Stochastic Subspace Identification (SSI) method (Figure 13). EFDD is a frequency domain technique based on the traditional PP and FDD methods. Its main advantage with respect to the previous ones is that close modes can be identified with high accuracy, even in the case of strong noise contamination of the signals. This technique also clearly indicates harmonic components in the response signals $[20,21]$. With regard to SSI, it is a method developed in the time domain. This method is still much faster than other nonlinear methods that are usually proposed to estimate the modal parameters from operational data $[22,23]$. The resolution of the spectral density estimation was defined as 1024 , which results in a frequency line spacing of $0.005 \mathrm{~Hz}$. Harmonic detection algorithms were also applied in order to check all the frequencies in the spectrum.

In this way, the modal frequencies, the damping ratios, and the mode shapes were obtained and then validated using the Modal Assurance Criterion (MAC) between the EFDD and SSI results [24]. The MAC value is defined as follows:

$$
\operatorname{MAC}_{j, k}=\frac{\left(\varphi_{j}^{T} \cdot \varphi_{k}\right)^{2}}{\left(\varphi_{j}^{T} \cdot \varphi_{j}\right) \cdot\left(\varphi_{k}^{T} \cdot \varphi_{k}\right)},
$$

where $\varphi_{j}$ and $\varphi_{k}$ are the two modes to be compared and $T$ denotes the transpose. A good correlation between two modes is achieved when the MAC ratio is greater than 0.85 . Data processing results, including the standard deviation of modal frequencies and damping ratios, are presented in Tables 1 and 2 (natural frequencies $(f)$, damping ratios $(\xi)$, and standard deviation (std)). 


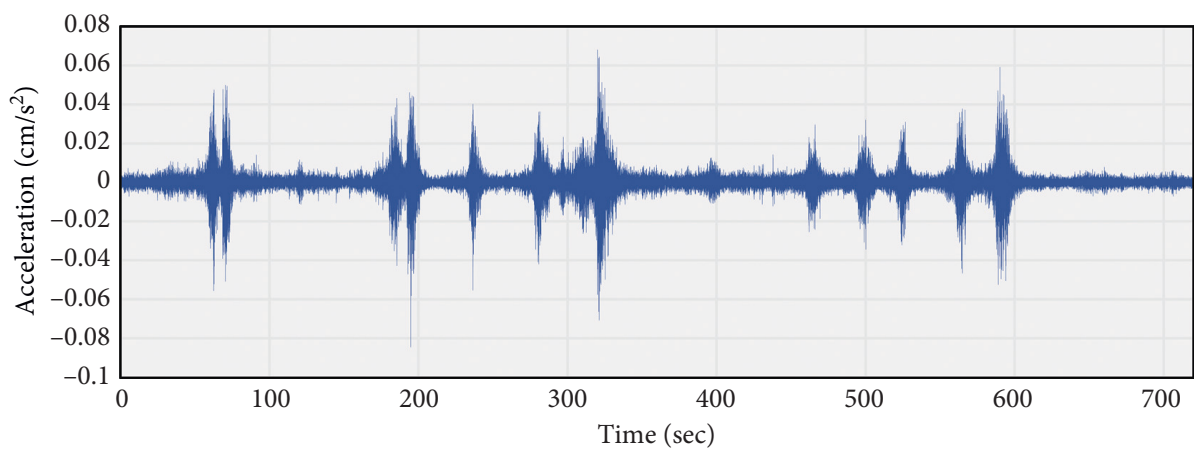

FIgURE 7: Time-history response (example of level of ambient excitation, accelerometer 4, and 3rd setup).

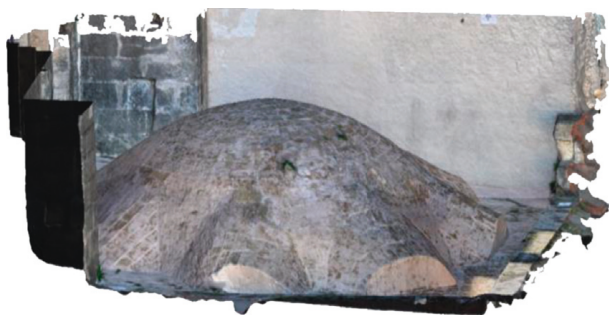

(a)

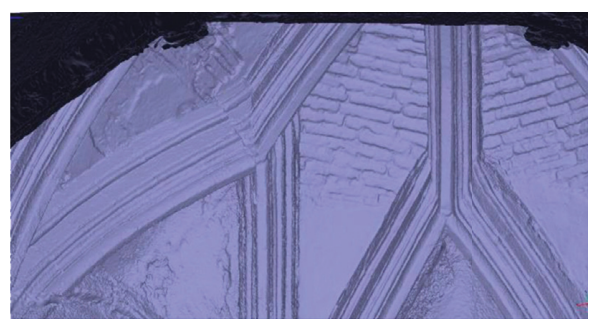

(b)

FIGURE 8: Geometric model using the photogrammetric technique.

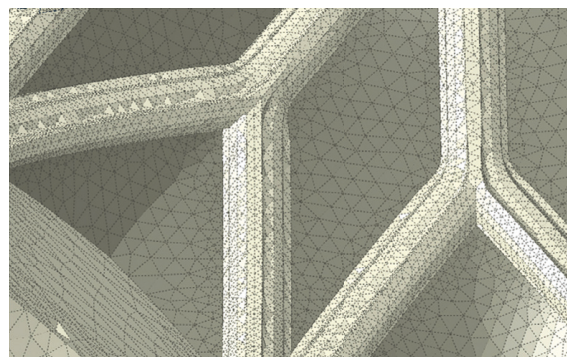

(a)

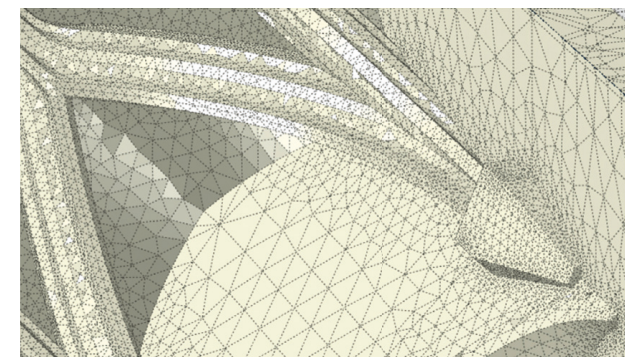

(b)

FIgUre 9: Finite element model.
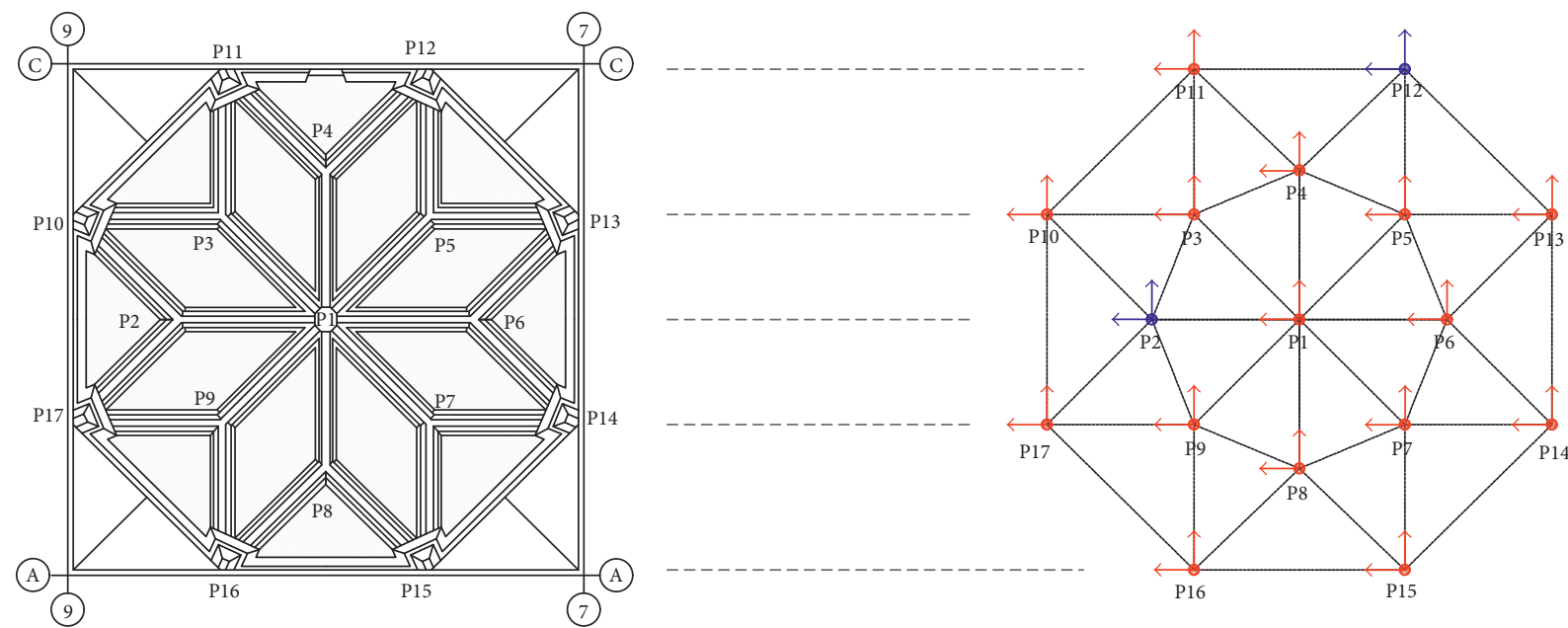

FIgURE 10: Accelerometer locations and directions on the intrados. 


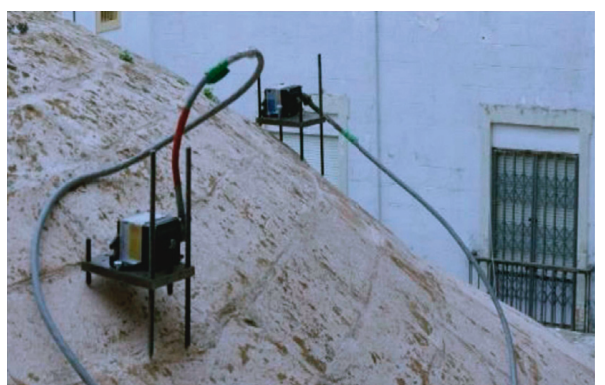

(a)

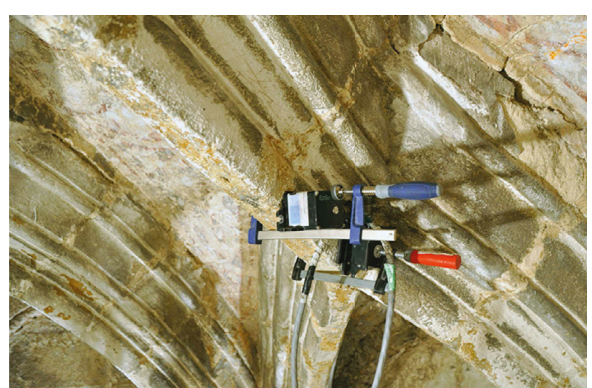

(b)

Figure 11: Accelerometers on the extrados and the intrados of the vault.

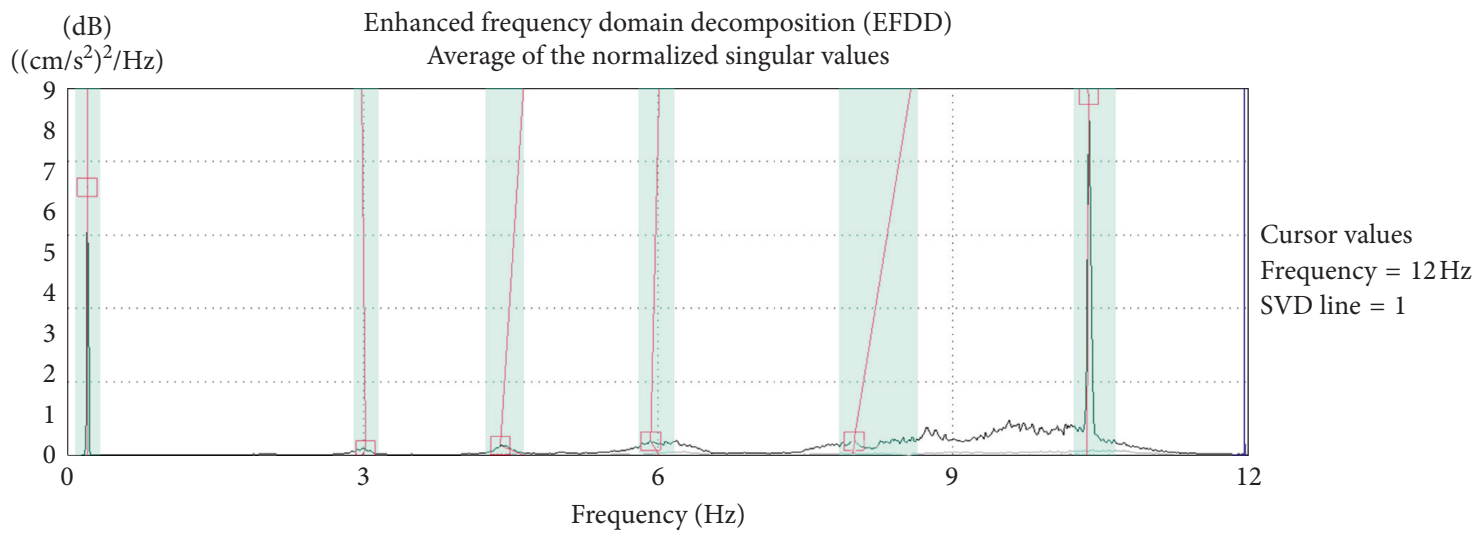

Indicators

Estimated mode

Modal domain

(a)

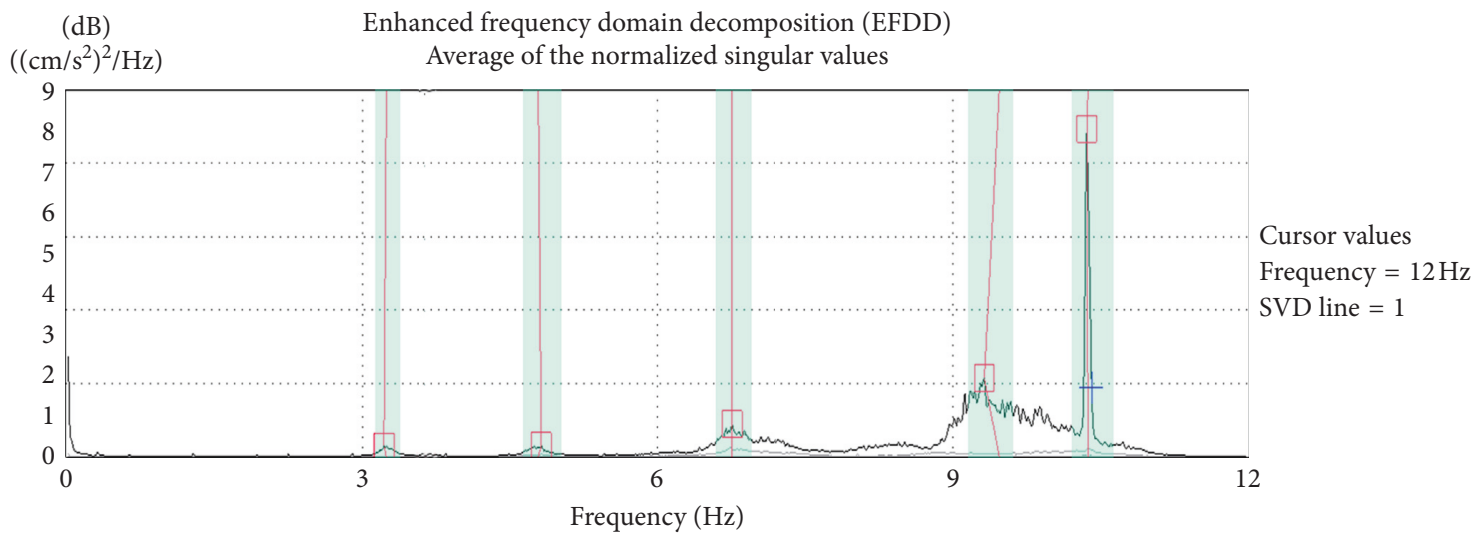

Indicators

Estimated mode

Modal domain

(b)

FIGURE 12: Ambient tests before and after works: intrados of the vault (EFDD).

\section{Analysis and Comparison of Results}

Results have been analysed and compared by following two different approaches. The first one is in line with the main purpose of this study, that is, the assessing of changes on the structural health of the chapel caused by the consolidation process, so focuses on the results that were obtained from the experimental campaigns that were performed from the vault intrados before and after the intervention. On the other hand, the second approach will compare results extracted from the four experimental campaigns in order to satisfy the secondary objective of this work, that is, to demonstrate the 


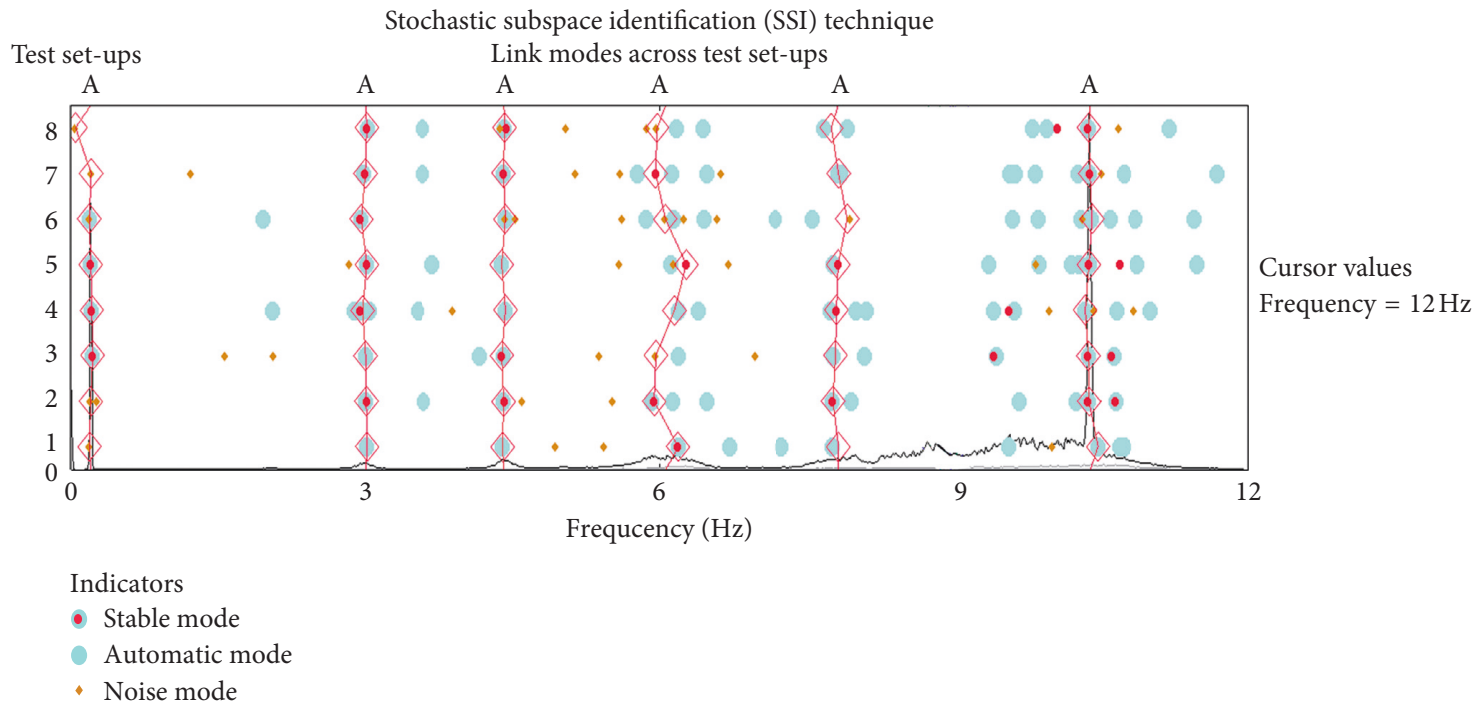

(a)

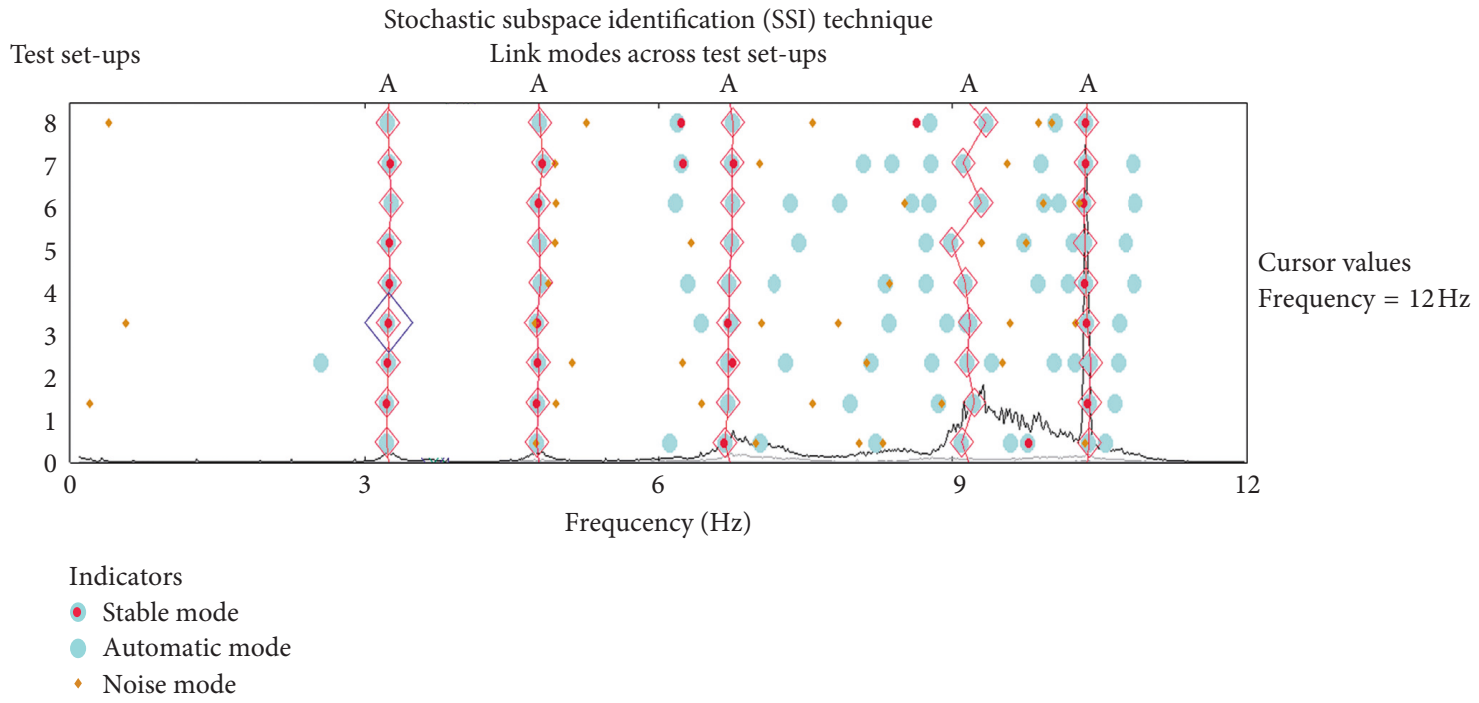

(b)

Figure 13: Ambient tests before and after works: intrados of the vault (SSI).

TABLE 1: OMA results before the works: natural frequencies $(f)$, damping ratios $(\xi)$, and standard deviation (std).

\begin{tabular}{|c|c|c|c|c|c|c|c|c|c|}
\hline \multirow{2}{*}{ Mode number } & \multicolumn{4}{|c|}{ SSI } & \multicolumn{4}{|c|}{ EFDD } & \multirow{2}{*}{ MAC } \\
\hline & $f(\mathrm{~Hz})$ & $\operatorname{std}(f)$ & $\xi(\%)$ & $\operatorname{std}(\xi)$ & $f(\mathrm{~Hz})$ & $\operatorname{std}(f)$ & $\xi(\%)$ & $\operatorname{std}(\xi)$ & \\
\hline \multicolumn{10}{|c|}{ Extrados of the vault } \\
\hline 1 & - & - & - & - & - & - & - & - & - \\
\hline 2 & 3.00 & 0.02 & 2.74 & 0.52 & 3.34 & 1.03 & 3.03 & 1.36 & 0.92 \\
\hline 3 & 4.71 & 0.65 & 2.96 & 0.80 & 4.83 & 0.76 & 1.75 & 1.26 & 0.85 \\
\hline 4 & 5.81 & 0.62 & 4.03 & 0.88 & 6.06 & 0.11 & 1.80 & 1.40 & 0.88 \\
\hline 5 & 8.60 & 0.78 & 3.11 & 1.11 & 8.37 & 0.79 & 1.04 & 1.00 & 0.79 \\
\hline 6 & 10.1 & 0.39 & 2.80 & 0.43 & 10.2 & 0.47 & 0.73 & 1.03 & 0.69 \\
\hline \multicolumn{10}{|c|}{ Intrados of the vault } \\
\hline 1 & 0.20 & 0.02 & 4.62 & 0.95 & 0.19 & 0.00 & 3.64 & 0.24 & 0.88 \\
\hline 2 & 2.99 & 0.02 & 3.00 & 0.41 & 2.97 & 0.02 & 2.75 & 0.27 & 0.98 \\
\hline 3 & 4.41 & 0.01 & 2.35 & 0.45 & 4.59 & 0.06 & 1.16 & 0.10 & 0.91 \\
\hline 4 & 6.00 & 0.09 & 4.16 & 1.28 & 6.00 & 0.07 & 1.84 & 1.19 & 0.89 \\
\hline 5 & 7.82 & 0.02 & 2.84 & 0.34 & 8.02 & 0.12 & 0.73 & 0.02 & 0.85 \\
\hline 6 & 10.4 & 0.04 & 0.95 & 0.97 & 10.4 & 0.03 & 0.27 & 0.34 & 0.98 \\
\hline
\end{tabular}


TABLE 2: OMA results after the works: natural frequencies $(f)$, damping ratios $(\xi)$, and standard deviation (std).

\begin{tabular}{|c|c|c|c|c|c|c|c|c|c|}
\hline \multirow{2}{*}{ Mode number } & \multicolumn{4}{|c|}{ SSI } & \multicolumn{4}{|c|}{ EFDD } & \multirow{2}{*}{ MAC } \\
\hline & $f(\mathrm{~Hz})$ & $\operatorname{std}(f)$ & $\xi(\%)$ & $\operatorname{std}(\xi)$ & $f(\mathrm{~Hz})$ & $\operatorname{std}(f)$ & $\xi(\%)$ & $\operatorname{std}(\xi)$ & \\
\hline \multicolumn{10}{|c|}{ Extrados of the vault } \\
\hline 1 & - & - & - & - & - & - & - & - & - \\
\hline 2 & 3.28 & 0.02 & 3.31 & 0.44 & 3.27 & 0.01 & 2.34 & 0.71 & 0.99 \\
\hline 3 & 4.81 & 0.03 & 2.31 & 0.69 & 4.82 & 0.03 & 1.06 & 0.66 & 0.89 \\
\hline 4 & 7.20 & 0.03 & 3.01 & 0.34 & 7.22 & 0.14 & 2.72 & 1.46 & 0.85 \\
\hline 5 & 8.97 & 0.16 & 2.70 & 0.42 & 8.97 & 0.08 & 2.42 & 1.56 & 0.84 \\
\hline 6 & 10.4 & 0.01 & 1.32 & 0.51 & 10.4 & 0.09 & 2.15 & 1.72 & 0.99 \\
\hline \multicolumn{10}{|c|}{ Intrados of the vault } \\
\hline 1 & - & - & - & - & - & - & - & - & - \\
\hline 2 & 3.24 & 0.01 & 3.33 & 0.59 & 3.23 & 0.01 & 2.03 & 0.37 & 0.99 \\
\hline 3 & 4.77 & 0.02 & 2.58 & 0.60 & 4.77 & 0.03 & 0.96 & 0.32 & 0.92 \\
\hline 4 & 7.24 & 0.09 & 4.82 & 0.62 & 7.20 & 0.04 & 0.77 & 0.31 & 0.87 \\
\hline 5 & 8.96 & 0.02 & 3.82 & 0.64 & 9.01 & 0.11 & 1.79 & 0.01 & 0.81 \\
\hline 6 & 10.4 & 0.04 & 0.40 & 0.52 & 10.4 & 0.07 & 0.12 & 0.34 & 0.99 \\
\hline
\end{tabular}

hypothesis according to which taking measurements from the extrados of a vault is not valid when a suspicion of disconnection between ribs and web exists.

6.1. First Approach. As shown in Tables 1 and 2, the ambient vibration tests performed from the intrados of the vault before and after consolidation works, allowed us to accurately identify six and five modes, respectively, in a frequency range from 0 to $12 \mathrm{~Hz}$. The frequencies were identified with relative errors lower than $4.0 \%$, taking as a reference the results of both methods. The results for the damping ratio show as higher variability as their standard deviations indicate. This result is not surprising, and higher excitation seems to be required in order to obtain reliable measures of damping [25]. The damping values obtained by the EFDD method are even less reliable than those obtained by the SSI method, as can be extracted from their higher standard deviation values. With respect to the mode shapes, the MAC indicates a good correlation between the identified modes, with values always higher than 0.80 for all collected data.

As shown in Table 3, the differences between the natural frequencies are highly significant. It can be noted that the first vibration mode, identified before the intervention (about $0.2 \mathrm{~Hz}$ ), is a vibration mode whose associated frequency is very low for this type of structure. The explanation of the existence of this mode is the crack on the rib that can be seen in Figure 4. In this case, the mode shape shows the free movement of the rib under the excitation frequency. Once the consolidation works were carried out, it can be observed that this vibration mode disappears, confirming the connection between elements.

In addition to the above comments, the comparison of the experimental data measured before and after the works shows how each one of the vibration modes significantly increases its own natural frequency (between about 3\% and $20 \%$ ), with the exception of the sixth mode, which does not change its associated natural frequency (Table 3 ). This fact leads us to conclude that the rigidity of the structure of the Jura Chapel after consolidation works has also increased, overall taking into account the aforementioned original
TABLE 3: Comparison of modal results before and after restoration works.

\begin{tabular}{|c|c|c|c|c|}
\hline \multirow{2}{*}{$\begin{array}{l}\text { Mode } \\
\text { number }\end{array}$} & \multicolumn{2}{|c|}{ Natural frequency (EFDD, Hz) } & \multirow{2}{*}{$\%$ dif. } & \multirow{2}{*}{ MAC } \\
\hline & Before works & After works & & \\
\hline 1 & 0.198 & - & - & - \\
\hline 2 & 2.977 & 3.238 & +8.76 & 0.93 \\
\hline 3 & 4.598 & 4.776 & +3.85 & 0.80 \\
\hline 4 & 6.007 & 7.205 & +19.94 & 0.89 \\
\hline 5 & 8.029 & 9.010 & +12.21 & 0.85 \\
\hline 6 & 10.40 & 10.40 & +0.00 & 0.98 \\
\hline
\end{tabular}

mass increasing (about 12\%) and according to (1). Meanwhile, MAC values were always higher than 0.80 , which indicate a good modal correlation between both experimental campaigns. As can be seen in Figure 14, the mode shapes, with the exception of the first mode, are very similar before and after the works, which means that the final structural behaviour of the vault has not changed in relation to the previous one.

6.2. Second Approach. By comparing results from experimental campaigns (Table 4), a significant reduction of the difference between frequencies from extrados and intrados can be observed after consolidation works. Thus, the maximum difference before the intervention is of $12.6 \%$ (Table 4, second mode) while, after the connection of the vault elements, this difference only reaches a maximum of $1.23 \%$ (Table 4 , second mode).

In addition to an analysis based on frequencies, there are two other relevant aspects which should be considered in order to assess the suitability or not of taking measurements from the extrados of a vault when ribs and web are disconnected. Tables 1 and 2 are useful to attend these aspects. The first aspect is referred to the standard deviation values which are associated with the obtained frequencies. These values are high in measurements from extrados before intervention works and for both SSI and EFDD methods, with maximums of 0.78 and 1.03 , respectively (Table 1 ). These standard deviation values are much more lower for 

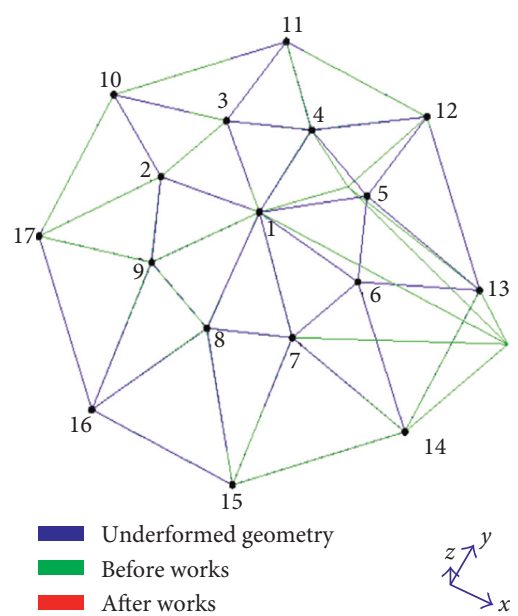

(a)
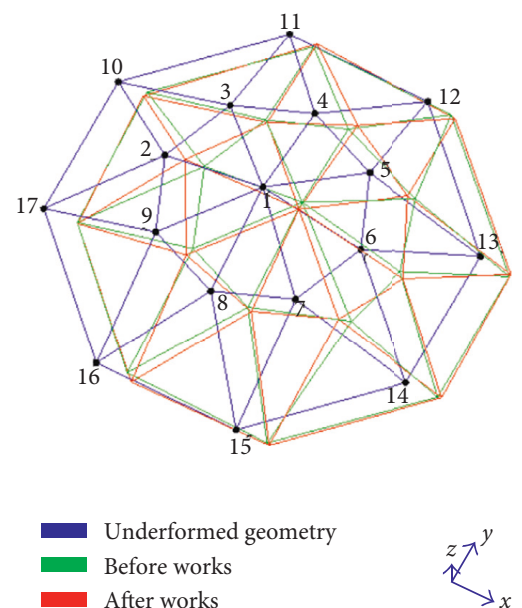

(d)
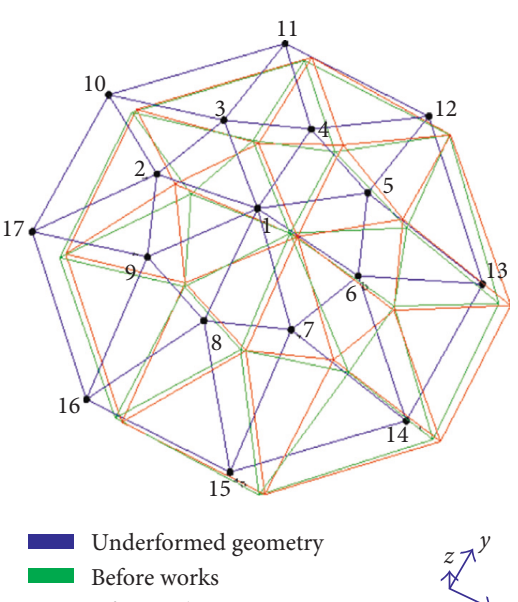

After works

(b)
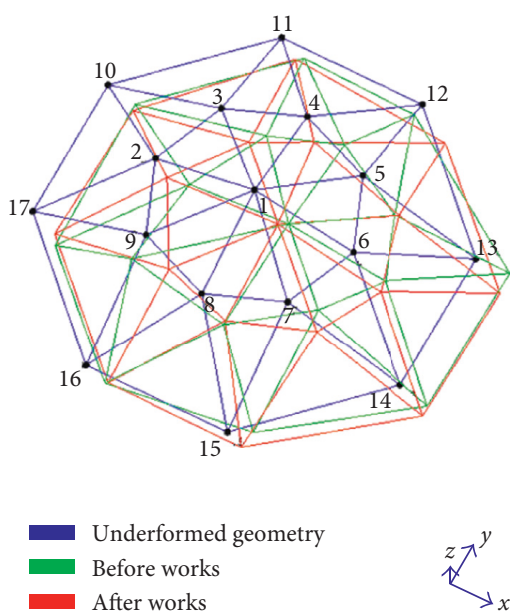

(e)
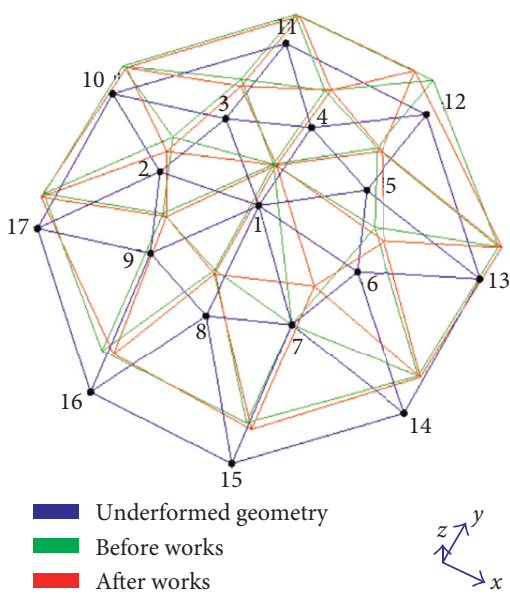

(c)
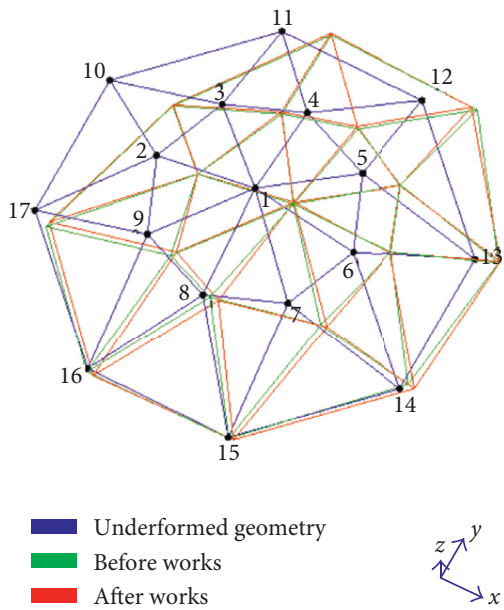

(f)

Figure 14: The first six-mode shape of the vault for the damaged and repaired cases. (a) 1st mode, (b) 2nd mode, (c) 3rd mode, (d) 4th mode, (e) 5th mode, and (f) 6th mode.

TABle 4: Comparison of modal results on the intrados and the extrados of the vault.

\begin{tabular}{lcccccc}
\hline $\begin{array}{l}\text { Mode } \\
\text { number }\end{array}$ & \multicolumn{2}{c}{$\begin{array}{c}\text { Frequency before works } \\
\text { (EFDD, Hz) }\end{array}$} & \multicolumn{3}{c}{$\begin{array}{c}\text { Frequency after works } \\
\text { (EFDD, Hz) }\end{array}$} \\
& Extrados & Intrados & \% dif. & Extrados & Intrados & \% dif. \\
\hline 1 & - & 0.19 & - & - & - & - \\
2 & 3.34 & 2.97 & 12.6 & 3.27 & 3.23 & 1.23 \\
3 & 4.83 & 4.59 & 5.22 & 4.82 & 4.77 & 1.04 \\
4 & 6.06 & 6.00 & 1.00 & 7.22 & 7.20 & 0.27 \\
5 & 8.37 & 8.02 & 4.36 & 8.97 & 9.01 & 0.44 \\
6 & 10.20 & 10.40 & 1.96 & 10.42 & 10.40 & 0.19 \\
\hline
\end{tabular}

frequencies that were obtained after intervention, with maximums of 0.16 (SSI) and 0.14 (EFDD) (Table 2). Meanwhile, standard deviation does not undergo significant variations before and after works when measurements are obtained from intrados. The second aspect is referred to the MAC improvement for measurements from extrados. Thus and as Table 1 shows, there are MAC values, which are lower than 0.80 before intervention ( 0.79 for mode 5 and 0.69 for mode 6), while after connecting ribs and web, all MAC values are above 0.84 (Table 2). Variations of MAC values for measurements from intrados and before and after works are not significant (Tables 1 and 2). On the other hand, it is also observed that the first vibration mode was not identified before consolidation works when the experimental campaign was performed from vault extrados.

\section{Conclusions}

This paper focuses on the Jura Chapel, in San Juan de los Caballeros Church (Cádiz, Spain), in order to assess the changes on its structural health after some consolidation works that took place in 2015 and by using nondestructive techniques, based on ambient vibration tests and Operational Modal Analysis. The dynamic behaviour of its vault has been assessed before and after these works.

Firstly, Operational Modal Analysis technique appears as a useful and nondestructive tool for identifying the dynamic parameters of historical masonry structures, such as ribbed vaults. The ambient vibration tests allowed to accurately 
identify up to six modes in a frequency range from 0 to $12 \mathrm{~Hz}$. It is enough number of modes to carry out the purposed analysis, due to interventions on these structures mainly impact on the first vibration modes.

The frequencies were identified with relative errors of less than $4.0 \%$, taking as a reference the results of both methods (SSI and EFDD). With respect to the mode shapes, the MAC values were always higher than 0.80 for all collected data. Both aspects reveal that the identification is enough accurate to consider as valid the variations in modal parameters after the intervention.

According to the results with regard to frequency values and mode shapes, and considering (1), the stiffness of the structure has increased after the consolidation works without modifying its original natural movement. In addition, the disappearance of the first vibration mode after the intervention confirms the connection between the ribs and the vault web.

It is confirmed the importance of considering existing structural damages in the way of designing the experimental campaign. In the case of this chapel, and considering the initial disconnection between elements in the vault, the most suitable experimental campaign before consolidation works was that performed from intrados. However, once the structure was consolidated, it has been proved that taking measurements from intrados or from extrados is indifferent. In this sense, it can be pointed out that frequency error between extrados and intrados campaigns before intervention reaches $12.6 \%$ (Table 4, mode 2), while after intervention, the same error is reduced in every modes, with maximum differences of $1.23 \%$ (Table 4, mode 2).

\section{Data Availability}

The data used to support the findings of this study are available from the corresponding author upon request.

\section{Conflicts of Interest}

The authors declare that there are no conflicts of interest regarding the publication of this paper.

\section{Acknowledgments}

The authors thank the property and the contractor for their support and availability during the ambient vibration tests carried out during the different construction phases.

\section{References}

[1] L. Ramos, Damage identification on masonry structures based on vibration signatures, Ph.D. thesis, University of Minho, Braga, Portugal, 2007.

[2] P. Pachón, Structural assessment of historical buildings by using the operational modal analysis (OMA) technique, Ph.D. thesis, University of Seville, Sevilla, Spain, 2016.

[3] C. Gentile and A. Saisi, "Operational modal testing of historic structures at different levels of excitation," Construction and Building Materials, vol. 48, pp. 1273-1285, 2013.

[4] K. K. Wijesundara, C. Negulescu, and E. Foerster, "Estimation of modal properties of low-rise buildings using ambient excitation measurements," Shock and Vibration, vol. 2015, Article ID 173450, 18 pages, 2015.

[5] R. Aguilar, R. Marques, K. Sovero, C. Martel, F. Trujillano, and R. Boroschek, "Investigations on the structural behaviour of archaeological heritage in Peru: from survey to seismic assessment," Engineering Structures, vol. 95, pp. 94-111, 2015.

[6] D. Foti, M. Diaferio, N. I. Giannoccaro, and M. Mongelli, "Ambient vibration testing, dynamic identification and model updating of a historic tower," NDT \& E International, vol. 47, pp. 88-95, 2012.

[7] L. F. Ramos, R. Aguilar, P. B. Lourenço, and S. Moreira, "Dynamic structural health monitoring of Saint Torcato church," Mechanical Systems and Signal Processing, vol. 35, no. 1-2, pp. 1-15, 2013.

[8] E. Ercan and A. Nuhoglu, "Identification of historical veziragasi aqueduct using the operational modal analysis," The Scientific World Journal, vol. 2014, Article ID 518608, 8 pages, 2014.

[9] M. Diaferio, D. Foti, N. I. Giannoccaro, and S. Ivorra, "Optimal model through identified frequencies of a masonry building structure with wooden floors," Journal of Mechanics, vol. 8, no. 1, pp. 282-288, 2014.

[10] D. Foti, M. Diaferio, N. I. Giannoccaro, and S. Ivorra, "Structural identification and numerical models for slender historical structures," in Handbook of Research on Seismic Assessment and Rehabilitation of Historic Structures, pp. 674-703, IGI Global, Hershey, PA, USA, 2015.

[11] P. Pachón, V. Compán, E. Rodríguez-Mayorga, and A. Sáez, "Control of structural intervention in the area of the Roman Theatre of Cadiz (Spain) by using non-destructive techniques," Construction and Building Materials, vol. 101, pp. 572-583, 2015.

[12] G. Osmancikli, Ş. Uçak, F. N. Turan, T. Türker, and A. Bayraktar, "Investigation of restoration effects on the dynamic characteristics of the Hagia Sophia bell-tower by ambient vibration test," Construction and Building Materials, vol. 29, pp. 564-572, 2012.

[13] İ. Çalık, A. Bayraktar, T. Türker, and H. Karadeniz, "Structural dynamic identification of a damaged and restored masonry vault using ambient vibrations," Measurement, vol. 55, pp. 462-472, 2014.

[14] J. Jacome and J. Antón, "La capilla de la jura de San Juan de los Caballeros, de Jerez de la Frontera: entre la épica y la realidad histórica," Revista de Historia de Jerez, vol. 13, pp. 183-212, 2007.

[15] A. Álvarez, M. Romero, and J. Guerrero, La Intervención en El Patrimonio: El Caso de las Iglesias Jerezanas (1850-2000), Vol. 378, Servicio de Publicaciones, Ayuntamiento de Jerez, Jerez, Spain, 2003.

[16] S. Atamturktur, L. Bornn, and F. Hemez, "Vibration characteristics of vaulted masonry monuments undergoing differential support settlement," Engineering Structures, vol. 33, no. 9, pp. 2472-2484, 2011.

[17] L. Ramos, L. Marques, P. Lourenço, G. D. Roeck, A. CamposCosta, and J. Roque, "Monitoring historical masonry structures with operational modal analysis: two case studies," Mechanical Systems and Signal Processing, vol. 24, no. 5, pp. 1291-1305, 2010.

[18] A. P. Ramos and G. R. Prieto, " 3 d virtualization by close range photogrammetry indoor gothic church apses. The case study of church os San Francisco in Bentazos (La Coruña, Spain)," ISPRS-International Archives of the Photogrammetry, Remote Sensing and Spatial Information Sciences, vol. XL-5/W4, pp. 201-206, 2015. 
[19] S. V. Solutions, Artemis Modal 5.0, User's Guide, Structural Vibration Solutions, Aalborg, Denmark, 2015.

[20] R. Brincker, L. Zhang, and P. Andersen, "Modal identification of output-only systems using frequency domain decomposition," Smart Materials and Structures, vol. 10, no. 3, pp. 441-445, 2000.

[21] T. Wang, O. Celik, F. Catbas, and L. Zhang, "A frequency and spatial domain decomposition method for operational strain modal analysis and its application," Engineering Structures, vol. 114, pp. 104-112, 2016.

[22] B. Peeters and G. D. Roeck, "Stochastic system identification for operational modal analysis: a review," Journal of Dynamic Systems, Measurement, and Control, vol. 123, no. 4, p. 659, 2001.

[23] B. Peeters and G. de Roeck, "Reference-bases stochastic subspace identification for output-only modal analysis," Mechanical Systems and Signal Processing, vol. 13, no. 6, pp. 855-878, 1999.

[24] R. J. Allemang and D. L. Brown, "A correlation coefficient for modal vector analysis," in Proceedings of 1st International Modal Analysis Conference, pp. 110-116, Orlando, FL, USA, November 1982.

[25] P. Brewick and A. Smyth, "An investigation of the effects of traffic induced local dynamics on global damping estimates using operational modal analysis," Mechanical Systems and Signal Processing, vol. 41, no. 1-2, pp. 433-453, 2013. 


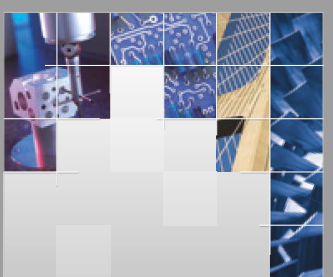

\section{Enfincering}
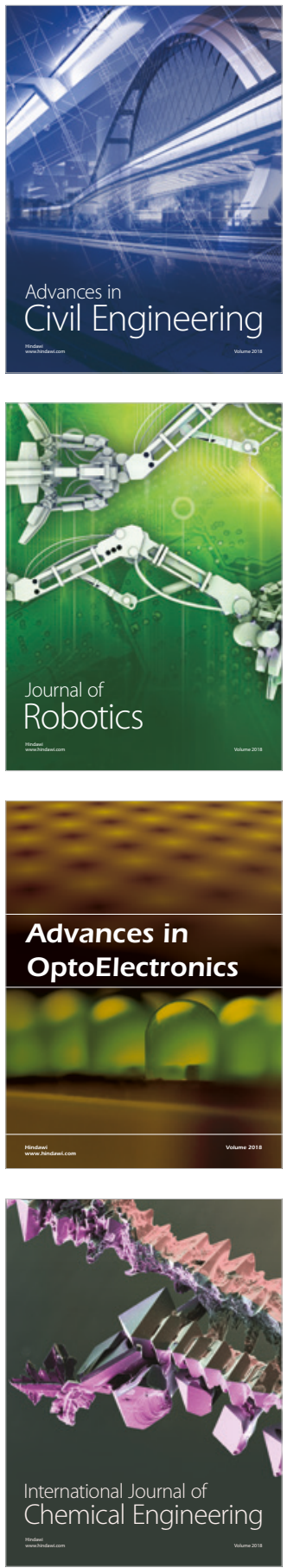

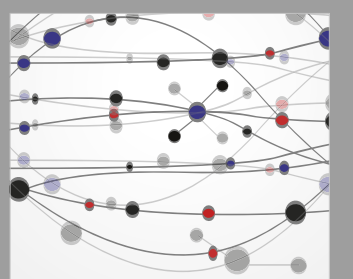

\section{Rotating \\ Machinery}

The Scientific World Journal

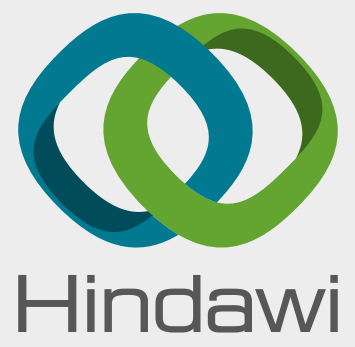

Submit your manuscripts at

www.hindawi.com
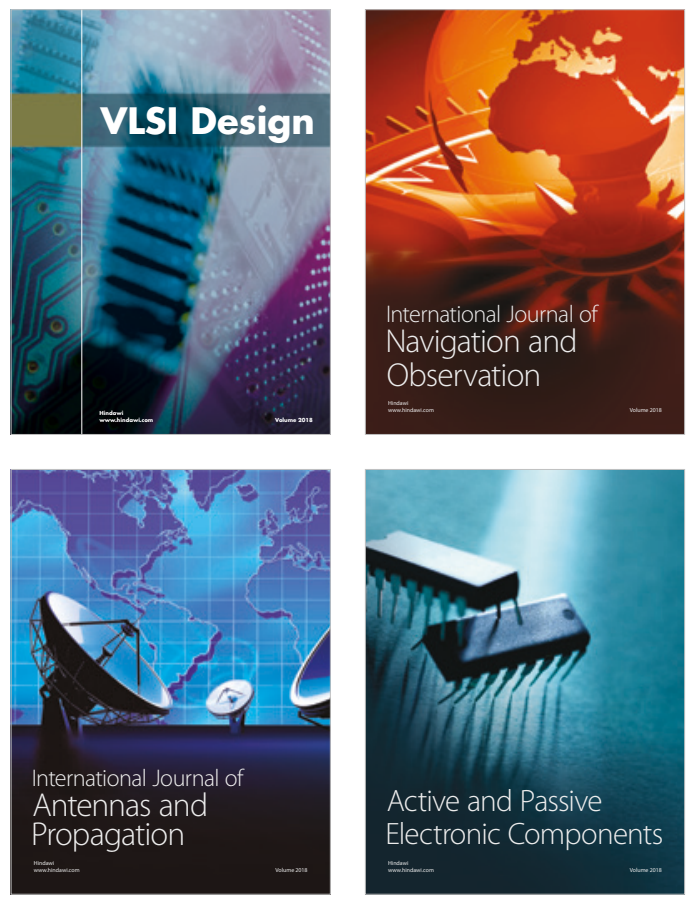
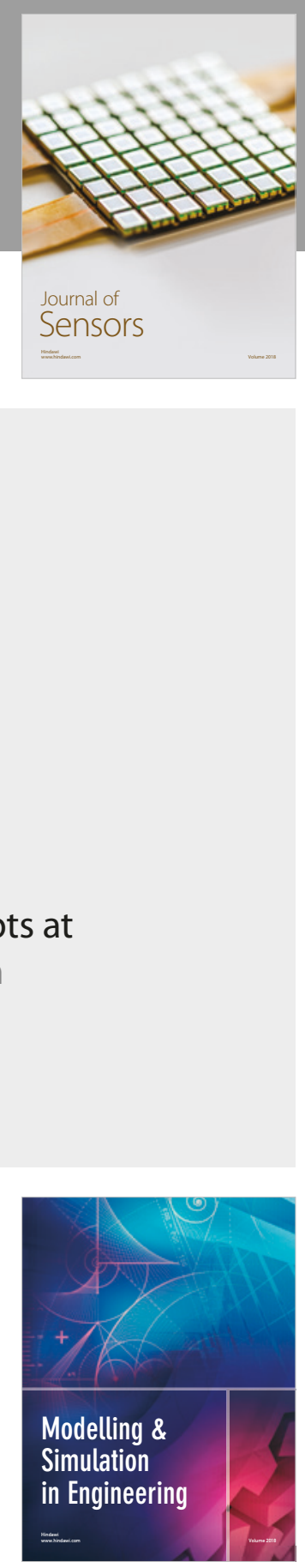

\section{Advances \\ Multimedia}
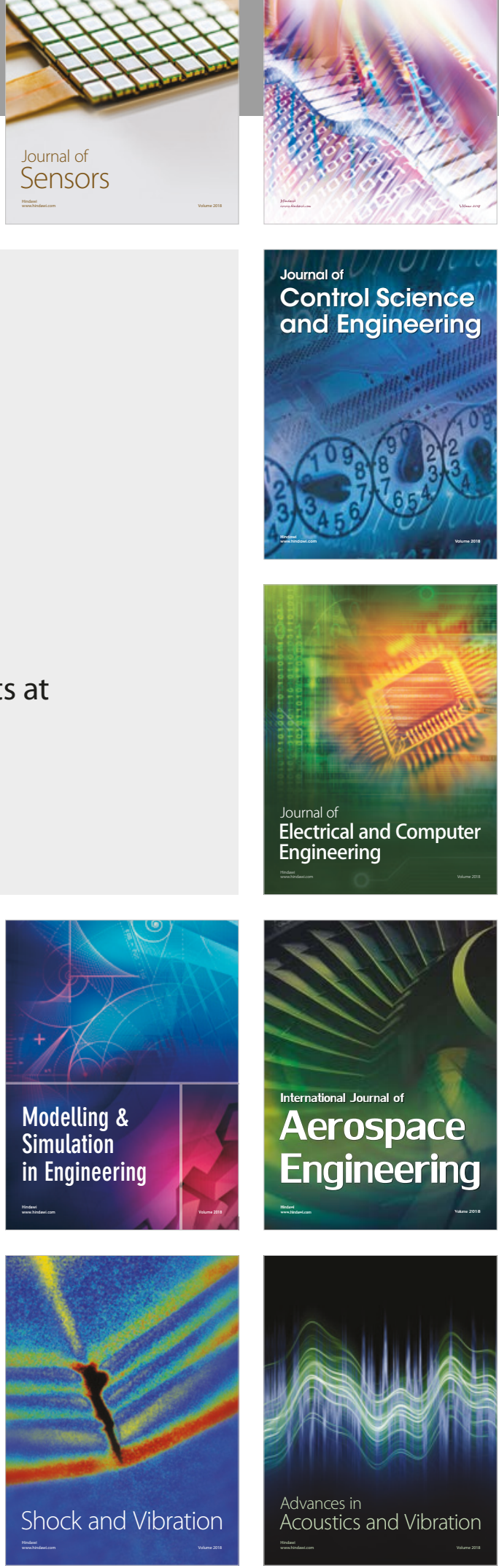